\title{
A criança surda: a infância na constituição de um espaço pedagógico que se ocupe da diferença
}

\author{
Lucyenne Matos da Costa Vieira Machado* \\ Sonia Lopes Victor ${ }^{* *}$
}

\section{Resumo}

Este texto tem como objetivo discutir a infância e a surdez como invençôes do nosso tempo que criam em crianças que transitam entre e nestes dois espaços a condição de sobreviventes dessas fronteiras. O objetivo principal deste trabalho permitiu pensar a infância como a condição de criação do espaço pedagógico, espaço que deve se ocupar com a diferença surda. Ao dialogarmos com as histórias de vida de duas crianças surdas e suas representações no espaço educacional, percebemos/tornamos possível que se perceba que as formas como esses indivíduos são conduzidos estáo intrinsicamente ligadas a como eles são constituídos e concebidos tanto no texto da lei quanto nos documentos da comunidade surda. A obsessão pelo corpo infantil do sujeito surdo está ligada à ideia de normalização imputada a esses sujeitos, já que é considerado que a educação precoce é fundamental para qualquer possibilidade de condução de suas subjetividades: tanto uma subjetividade surda quanto uma subjetividade ouvinte. E, a partir dessas reflexôes, este texto presume que perceber a criança como sobrevivente dessas fronteiras possibilita construir espaços pedagógicos capazes de levar em conta a materialidade que constitui esse sujeito a partir da sua tríplice potência (movimento, palavra e pensamento) e capacidade de sua exposição.

Palavras-chave: Infância; Surdez; Diferença.

* Professora doutora da Universidade Federal do Espírito Santo, Vitória, Espírito Santo, Brasil.

** Professora doutora da Universidade Federal do Espírito Santo, Vitória, Espírito Santo, Brasil. 


\section{A deaf child: childhood in the establishment of an educational space that occupies the difference}

\section{Abstract}

This text aims to discuss childhood and deafness as inventions of our time which creates in children the survivor condition. The main objective of this paper allowed us to think about a pedagogical space (according to Masschelein and Simons, 2014), which engages in the deaf difference within early childhood education. Based on life stories of two deaf children and their representations in the educational space, one can realize that their life conditions are conducted and intrinsically linked to how they are made and designed according to the law and to the documents of the deaf community as well. The obsession with children's body deaf subject is based on the idea of normalization allocated to these subjects since it is considered that early education is critical to driving any possibility of their subjectivities: both deaf subjectivity and the listener subjectivity. And from these reflections, this paper assumes that perceive the child as a survivor of these borders, enables us to build pedagogical space in order to take into account the materiality that constitutes this subject from its triple power (movement, speech and thought) and capacity of its exhibition.

Keywords: Childhood; Deafness; Difference.

\section{Para início de conversa...}

Como profissionais da educaçáo, conhecemos bem os discursos que tratam a surdez como uma marca e acabam por constituir, metaforicamente, um país. Como nos afirma Wrigley (1996, p. 12): "a surdez é um grande país, porém sem território". Além de considerarmos a surdez um grande país, a consideramos também uma grande invenção, tal qual o faz Lopes $(2007$, p. 7$)$, quando se refere a ela não "[...] como materialidade inscrita em um corpo, mas [...] como construção de um olhar sobre aquele que não ouve".

Assim como a surdez, o conceito de infância também nos é sugerido por Moacyr Scliar como um país, quando o autor escreve que "há um país chamado infância, cuja localização ninguém conhece ao certo" (SCLIAR, 1997, p. 3). Contribuindo para essa comparação entre a forma de pensarmos os dois termos, Bujes (2002) também considera o conceito de infância não como um dado atemporal, mas uma invenção/fabricação da modernidade.

Dessa forma, surdez e infância se relacionam aqui como invençôes/fabricaçóes da modernidade. O termo invenção é compreendido no sentido que traz Wittgenstein (2004 apud LOPES, 2007) pós virada linguística, quando declara que a linguagem denomina coisas, criando significados. Nessa direção, os discursos sobre a surdez, tanto no campo da clínica como no campo social, são constituídos histórica e culturalmente. Tomando como base a centralidade da cultura na constituição de significados, Lopes $(2007$, p. 7) reconhece que "todas as interpretaçóes possíveis so- 
bre o que convencionamos chamar surdez são interpretações sempre culturais", assim como o são os discursos sobre a infância que, segundo Bujes (2002), têm como marca o discurso da Pedagogia, da Psicologia e da Medicina, traçando "verdades incontestáveis" sobre a infância e desenvolvimento da criança.

Nesse sentido, tendo por base os apontamentos feitos até aqui, podemos destacar como o objetivo deste ensaio refletir a respeito da criança surda como sobrevivente nas fronteiras entre ser criança e ser surda e, também, refletir a respeito de como os discursos inventados nesses "países" fronteiriços sobre essa criança surda a constituem, e acabam por determinar muitas vezes as práticas pedagógicas desenvolvidas no campo escolar. Ademais, como também ocorre às práticas pedagógicas/clínicas desenvolvidas, essas práticas recriam a forma de ser criança surda circunscrita à infância.

\section{A infância como potência de vida e a institucionalização do corpo: apontamentos sobre políticas e atendimento clínico e pedagógico}

A infância da criança surda como tempo pré-existente era e ainda é considerada a melhor fase para "tratar" a "doença" surdez. Pesquisas e estatísticas das mais variadas vêm mostrando que a educação precoce é a forma mais completa de se instalar as tecnologias que são criadas para adequar o corpo surdo a uma reabilitação constante. Tanto que sua infância sempre fora traçada pela Medicina desde o seu nascimento. Assim que a família recebe o diagnóstico dessa criança, geralmente dada por um médico, o grupo procura o profissional da área de Fonoaudiologia para, como forma de superar a decepção da notícia, lançar mão de todas as tecnologias disponíveis e possíveis para que seu filho possa ouvir.

Para refletirmos sobre esse movimento, nos propomos aqui a trazer à tona a discussão de Masschelein e Simons (2014) a respeito da infância como potência de vida na construção de um espaço pedagógico/institucional.

Segundo o autor, é possível entender a infância como uma potencialidade, ou uma potência. Seria uma espécie de "vácuo que afasta o aluno de tudo aquilo que, como inteligibilidade, a ele se integra, isto é, de tudo que o representa na ordem da realidade e da compreensão" (MASSCHELEIN; SIMONS, 2014, p. 34).

Assim, tomando como base a noção de infância proposta por esse autor, nos propomos a tratar a questáo que se circunscreve à infância da criança surda de outro modo, compreendendo também que o vácuo de que Masschelein e Simons falam pode estar justamente na fronteira entre a criança e a surdez. Então, questionamos: como escapar da inteligibilidade que perpassa a discussão do corpo que precisa ser transformado?

Entendendo o corpo como espaço onde se inscrevem todas as possibilidades do devir sujeito, a infância passa a ser aquele momento de diferentes institucionalizaçóes. De acordo com Wrigley (1996), o corpo é um tema recorrente nos estudos da alteridade e da diferença, por isso, consideramos/o autor considera um erro pensar no corpo formado por apenas aspectos fisiológicos e que, além disso, ele escape à história. 
Ele é formado por "[...] regimes que o constroem; ele é destroçado por ritmos de trabalho, repouso e festa; ele é intoxicado por venenos - alimentos ou valores, hábitos alimentares e leis morais simultaneamente; ele cria resistências" (FOUCAULT, 2005, p. 27).

Entendemos dessa forma que, para além de mera constituição de fatores biológicos, a infância é histórica. $\mathrm{O}$ seu processo de construçáo se caracteriza pela tensão e pela contradição interna. A historicidade da infância continua em processo de construção, não por conta somente da entrada e saída dos seus atores, trazendo perspectivas de gerações diferenciadas, mas, principalmente, por conta da conjugação dos fatores internos e externos que a constroem e as dimensôes de que se compóem, dimensóes essas que não ocorrem sempre no mesmo sentido, trazendo um deslocamento do peso de suas variáveis continuamente, implicando mudanças (SARMENTO, 2005).

Tomando por base essa análise, o corpo da criança surda, sua infância inscrita, passa a ser desejado e, sobre ele, "expectativas tecnológicas" (BIESTA, 2013) são depositadas. Diferentes formas de trabalhar a deficiência dessa criança são criadas a fim de tornar seu corpo o mais próximo possível do corrigido. Devido a essa obsessáo no tratamento da surdez no espaço da infância, toda a perspectiva pedagógica passa a seguir os protocolos clínicos como única possibilidade de auxiliar nessa correção. $\mathrm{O}$ espaço pedagógico, que é capaz de produzir potência no sujeito, passa a perder valor, pois é inscrito sob outras bases.

Pensar que a infância é a condição de criação do espaço pedagógico nos termos de Masschelein e Simons (2014) tornaria necessário/necessitaria traduzi-la como potência e exposição. $\mathrm{O}$ autor ainda desdobra em tríplice potência: 1) "[...] a potência de movimento, isto é, o deslocamento do sujeito para fora de si ou vontade [...]" (MASSCHELEIN; SIMONS, 2014, p. 34), ou seja, vontade de se colocar a caminho, de se mover, de falar por si próprio, de se colocar como sujeito que se reconhece como capaz de agir por si próprio; 2) A potência da palavra ou da tradução, tendo a tradução a ver com compreender, ou com que confronta o falante a outro falante; E, por fim, 3) a potência do pensamento ou da reminiscência.

E, portanto, essa tríplice potência se desdobra numa "ex-posição". "A ex-posição remete ao surgimento das crianças como seres de palavra" (MASSCHELEIN; SIMONS, 2014, p. 35).

Mas o que significa seres de palavras? Significa dizer que são seres falantes, mas sobretudo e antes de qualquer outra coisa, que uma palavra humana lhe foi endereçada, a qual querem reconhecer e à qual querem responder [...] na condição de homens. Assim podese dizer que a infância como vácuo implica uma carga (ou uma dívida) de resposta. Ademais, um ser de palavra está exposto ao outro e às palavras dos outros. [...] e que só é possível falar de alguma coisa, falando a alguém. (MASSCHELEIN; SIMONS, 2014, p. 35). 
Nesse sentido, ao fazer uma analogia com o filme de Pedro Almadóvar, Góes (2008, s/p) problematiza: "Fale com ela"1, que o educador fale com essa criança e não apenas fale dela ou por ela. Para que, de fato, ela se constitua como um ser falante, de palavra e de potência, e fale de alguma coisa a alguém, exercendo a sua condição humana, conforme chamam-nos atenção Masschelein e Simons (2014).

$\mathrm{Na}$ contramão dessa ideia sustentada numa perspectiva da negatividade da infância, resumida na terminologia, na linguística e na jurisprudência sobre a criança e a infância a partir dos fatores de exclusão e não, prioritariamente, pelas características que as distinguem ou por efetivos direitos de participaçáo (SARMENTO, 2005), a criança foi excluída do espaço-tempo da vida em sociedade, sobretudo quando nos referirmos à criança em questão, a qual "[...] é dominada pela representação da deficiência mais do que pela representação da criança, com suas particularidades eventuais" (PLAISANCE, 2005, p. 405). Por isso, ainda conhecemos pouco das particularidades eventuais dessa criança, porque, historicamente, os estudiosos desse campo se detiveram em teorizar sobre a sua representação, construída a partir de estereótipos e estigmas, e não de sua potência ou de sua tríplice potência, fazendo surgir seres de palavra (MASSCHELEIN; SIMONS, 2014).

Nesse sentido, como nos afirma Costa (2007), a prescrição de práticas pedagógicas para crianças surdas pequenas, práticas essas que são divididas por graus de surdez, se constituiu como política educacional. Essa política marcou, por muito tempo, a criança surda, direcionando-a para uma condição produzida socialmente de normalidade. Consequentemente, as práticas educacionais pautadas na oralização eram organizadas por grupos, sendo feita essa organizaçáo de acordo com a perda auditiva da criança, indicada no exame de audiometria.

Por muito tempo, as alternativas de atendimento aos alunos surdos foram divididas pelos graus de perda auditiva: leve, moderada, severa e profunda. Uma grande importância sempre foi dada à normalização desses sujeitos surdos para que eles pudessem ser enquadrados na escola comum e no mundo dos ouvintes.

Por anos os surdos vêm apontando essas práticas como práticas pedagógicas/ clínicas que ditam a forma como a educaçáo desses sujeitos vem sendo organizada. Apontam a existência de um currículo audiológico-audiométrico nos termos de Skliar (1999), currículo que se serve de técnicas e recursos que conduzem todos os esforços institucionais para uma possível normalização dos sujeitos surdos.

Uma das principais mudanças ocorridas na condução de uma política educacional para os sujeitos surdos estão inscritas na Lei 10.436/02 e no Decreto 5.626/05 que instituem práticas necessárias para surdos desde a educaçáo infantil.

A referida lei, conhecida como a lei de Libras, e o referido decreto que a regulamentou já indicam a preocupação com a educação infantil, uma vez que as açôes são previstas inclusive para esse grupo. Acredita-se que ao atingir as crianças desse grupo, garantindo a aprendizagem da Língua Brasileira de Sinais, os problemas de aprendizagem dos conteúdos serão minimizados. 
Antes mesmo da lei e do decreto, vários documentos foram escritos, tentando nortear e construir uma possibilidade de prática docente em que a diferença surda pudesse ser respeitada e observada.

Vale citar o documento construído pela comunidade surda, por ocasião do pré-congresso latino americano de Educaçâo Bilíngue, ocorrido em 1998 em Porto Alegre, denominado: "A Educação que nós surdos queremos". No documento, as práticas pedagógicas específicas para a aquisiçẫo da língua de sinais são parte integrante do programa que garante o acesso aos conteúdos pelas crianças surdas. A infância é desejada e a obsessão por ela fica clara nos discursos dos educadores surdos e ouvintes. São parte desses discursos escolas bilíngues para surdos, classes bilíngues específicas para surdos, professores surdos e tecnologias visuais, por meio das quais a língua de sinais seria difundida.

Um outro documento, que ressalta o especificado acima, é o documento final do I Seminário "Surdos, um olhar sobre as práticas em Educação", que foi realizado em Caxias do Sul (RS) em setembro de 2001. Tal documento foi elaborado durante o referido seminário, numa tentativa de busca de temas/propostas de formação de surdos professores/profissionais de educação. Também nesse documento estão produçóes teóricas sobre o importante vínculo entre cultura e educação e a preferência por uma pedagogia da diferença.

Na parte em que o texto trata das práticas de escolarização, a educação infantil é instruída da seguinte forma para o educador surdo (foco do seminário):

\section{$\mathrm{Na}$ Educaçáo Infantil o professor/educador surdo deverá ter capacidade para:}

1. Saber trabalhar com a criança surda em educação infantil;

2. Ter conhecimentos de planejamento curricular para surdos na educação infantil;

3. Saber orientar a criança surda a ampliar o vocabulário em LIBRAS e oferecer a oportunidade de início ao sistema de escrita de sinais ( Sign Writing);

4. Saber iniciar na língua de sinais a criança surda que tem família ouvinte;

5. Ter didática de sequência lógica em LIBRAS para a criança surda;

6. Ter conhecimentos de como contar histórias infantis na língua de sinais.

Em contrapartida, também há a obsessão pelo corpo da criança surda na clínica, obsessão que se dá principalmente com as tecnologias, que tem se mostrado mais eficazes quando testadas em crianças surdas. Há uma "pressa" em propor medidas terapêuticas, estimulação precoce para resíduos auditivos, prótese auditiva, implantes cocleares, etc. Tudo com a perspectiva de que, quanto mais cedo a criança surda for estimulada, mais cedo "[...] a normalização faz com que sejam absorvidos, deixando de constituir um grupo à parte, segregado" (COUTO-LENZI, 1996, p. 18). 
Quando Gallo e Souza (2004) instigam seus leitores a perguntarem: Mas que infância é essa? Trazem a resposta de Pino (2004, p. 147): “[...] a infância é um produto cultural, isto é, produzimos nossas infâncias, espelhos nos quais, uma vez mais, nos vemos refletidos[...]". Assim, a criança surda é inventada nesse discurso entre o seu processo de reabilitação e a negação do sentido de infância.

Continuando na discussão com Gallo e Souza (2004, p. 20), a infância é narrada pelos autores como período de construçáo e retorno a nós mesmos, pensamento que é complementado pelos dois com um toque nostálgico: "Doce ilusão... as crianças devem ser elas mesmas. O que nos restaria entâo? Seguir-lhes os passos trôpegos, sem pretender endireitá-los, deixar que se equilibrem e, nesse jogo, brincar de equilibristas com elas, convidá-las a fazerem obras de arte".

É possível esse pensar a infância, mágica ou não, ingênua ou como constructo social, invenção moderna ou como um país, quando trato da criança surda? Para esse exercício, trouxemos duas histórias, a de Clara e João².

\section{Histórias de escola e de vida: quem é Clara?}

A história de Clara nos toca e mostra a vida nas fronteiras entre a infância e a surdez de forma intrigante.

Ao ver Clara pela primeira vez, as primeiras histórias que foram contadas sobre ela constavam nos diagnósticos clínicos. Clara, uma menina de cinco (5) anos, fora submetida ao implante coclear desde os três (3) anos e, de acordo com o diagnóstico descrito, tinha uma linguagem de uma criança de dois anos.

Clara não conhecia a língua de sinais e era proibida de estar entre surdos, mesmo crianças, o que era resultado do receio justamente de que aprendesse a se comunicar como eles.

Já a história que a professora da sala regular de Clara contava não ia ao encontro do diagnóstico descrito. Ela afirmava que Clara não ouvia e tinha uma dificuldade de interação muito grande com os colegas e com ela própria, pois utilizava recursos rudimentares de linguagem para solicitar coisas simples como ir ao banheiro e beber água. O diagnóstico da fonoaudióloga de Clara, afirmando que a mesma tinha uma linguagem de uma menina de três anos de idade, segundo a professora, não condizia com a realidade.

Para a família, Clara ouvia. Com o implante coclear, Clara teria a chance de ser uma "criança normal" (neste caso específico: ouvinte) e com certeza chegaria a falar e ouvir muito bem. Para a máe, Clara seria curada e estava a caminho disso. Precisava do acompanhamento da fonoaudióloga e a professora náo sabia lidar com ela por falta de preparo, porque a menina ouvia muito bem. E falava algumas palavras.

A partir dessas narrativas, nos perguntávamos: como Clara se constituía? E como as práticas com Clara iam sendo construídas?

E Clara por Clara? Não sabemos bem, mas era uma criança que brincava de pular corda e de pique. Uma criança que não conversava muito devido à dificuldade 
em ouvir. Uma menina procurando se comunicar de formas variadas com sua professora, lançando mão, inclusive, de gestos simples.

Não passamos muito tempo com Clara para pensarmos uma narrativa melhor. Só sabemos que a história com a mãe de Clara teve desdobramentos e muita conversa. Como sabemos também que, no fim da história, a opção é dos pais. E a mãe de Clara, reconhecendo o esforço tamanho a que submeteu a sua filha na cirurgia do implante coclear e no tratamento diário em que vivia na busca da língua oral, náo achava que mudar de postura agora seria o mais adequado.

Todavia, Lane (1998) afirma:

\begin{abstract}
A aquisição de língua oral é um importante objetivo do implante coclear em crianças - mais ainda porque estimativamente $86 \%$ de crianças com perdas profundas de audição as têm desde o nascimento, e a maioria provavelmente não adquiriria língua oral ou se comunicariam oralmente. Este é também um importante objetivo da cirurgia na visão de muitos pais que dão o consentimento. [...] muitos programas de implantes e livros para pais para lidarem com seus filhos implantados enfatizam a comunicação oral, incluindo a participação em programas educacionais orais, e buscam desencorajar a $[. .$.$] criança Surda em se comunicar em uma língua$ visual/manual. (LANE, 1998, p. 8).
\end{abstract}

A tecnologia do implante coclear era algo que marcava a vida e as atividades vividas por Clara e sua família. A qualidade da linguagem de Clara ainda não atendia as expectativas da escola, dos pais e de todos os envolvidos. Ela ainda precisaria de muitas seçóes com o fonoaudiólogo e atendimento especializado na escola.

Em relação às práticas pedagógicas dispensadas a Clara, elas ficam aquém do que a professora desejaria que fosse feito, deixando-a frustrada e mantendo Clara refém das expectativas em relação à tecnologia em que estava submetida, e que a torna um sujeito de puras possibilidades para o qual viver os resquícios de audição e a fala deficiente serão suas marcas da eterna busca da normalidade.

\title{
Histórias de escola e de vida: quem é João?
}

João era uma criança surda. Aos quatro anos de idade foi apresentado de uma forma que cada dia é mais comum em nosso tempo: a professora na escola de educação infantil estava perdida sobre como trabalhar com ele e sobre como investir na inclusão dele em sala de aula. Ao convocar a professora de educaçáo especial para "resolver o problema", ela táo pouco poderia pensar em como solucionar a equação que se apresentava. Naquele momento, a única coisa que ela propôs foi: ele deve aprender Libras.

João era narrado pela família como uma criança surda que brincava muito. Era genioso e persistente. Além disso, tinha um irmão mais velho que era surdo também e, por isso, a aceitação da surdez de ambos pelos pais se dava com o discurso da mãe: se Deus me deu filhos assim, ele me preparou para isso. 
Já na escola, João era narrado como uma criança surda que estava hospedada naquele lugar, no entanto, não sabiam como agir ou se comportar com ele. A professora de João tinha dificuldade de se relacionar com ele por não saber essa "linguagem das mãos".

Inicialmente, também a professora especialista convocada teve dificuldades de se comunicar com João porque os sinais que ele utilizava eram criados em casa para a comunicação entre a família. Por isso, foi preciso aprender esses sinais criados para começar a ensinar Libras para ele. A família começou a aprender a Libras e a entrar na comunidade surda e apresentá-lo a esse mundo. João aprendeu a Libras e, em pouco tempo, estava inserido na comunidade surda. As atividades na sala de aula eram trabalhadas colaborativamente entre a professora especialista e a professora da sala de aula regular. As práticas pedagógicas construídas visavam à aprendizagem das atividades propostas pela professora para a turma, à aprendizagem da Libras, à inclusão de Joáo entre os colegas ouvintes e à compreensão de todos sobre o mundo dos surdos.

Quando um encontro de João e outra criança surda de sua idade foi promovido, ele ficou intrigado e indagou sobre o porquê de seu amigo não saber Libras. Foi explicado a ele que a mãe do seu colega não deixava, pois ele usava aparelho auditivo. João disse que também usava aparelho auditivo e que então a mãe dele era muito boa porque ela o deixava usar Libras também.

João e Clara transitavam nesses dois países, da surdez e da infância, de formas diferentes por conta da linguagem, cada qual de uma forma.

Se a linguagem se constitui o principal meio de transporte entre esses dois mundos, quais seriam as condiçóes de possibilidades para que ambos pudessem habitar muito mais do que nas fronteiras, garantindo seu lugar em ambos os espaços, criando até um espaço comum onde a infância e a surdez se constituem como um espaço único e possível de ser habitado?

\section{Considerações finais}

Clara e João são crianças que exemplificam como o diagnóstico e a norma podem, por meio do discurso, narrar a infância da criança surda e ainda definir toda uma prática pedagógica, ou pelo menos que se diz pedagógica. Skliar (2003), em suas reflexôes sobre a deficiência, desconstrói em nós conceitos enraizados, forçando-nos a refletir sobre nossas açôes diante desse outro que nos constitui.

A presunção de que a deficiência é, simplesmente, um fato biológico e que apresenta características universais deveria ser, mais uma vez, problematizada epistemologicamente: compreender o discurso da deficiência, para logo depois revelar que o objeto desse discurso náo é a pessoa que está em uma cadeira de rodas ou aquela que usa prótese auditiva, ou aquela que não aprende segundo o ritmo e a forma como a norma espera, senáo os processos históricos, culturais, sociais e econômicos que regulam e controlam a maneira pela qual são pensados e inventados os corpos, as mentes, a linguagem, a sexualidade dos outros. Para expressá-lo de forma ainda mais contundente: a deficiência não é problema dos 
deficientes e/ou de suas famílias e/ou dos especialistas. A deficiência está relacionada à ideia de normalidade e à sua historicidade. (SKLIAR, 2003 , p. 158)

Skliar (2003) resumiu bem a nossa presunção em fixar o outro dentro dos limites da norma. Pois não é de se espantar que, até relativamente bem pouco tempo, os sujeitos da educação especial vinham sendo narrados, produzidos, criados pelos profissionais que trabalham com eles como se fossem objeto de estudo e curiosidade.

Para além de retomar essa história, como já mencionamos, o desafio deste ensaio é refletir a respeito da criança surda como sobrevivente nas fronteiras entre ser criança e ser surda e como os discursos inventados nesses "países" fronteiriços sobre essa criança surda a constituem, determinando, muitas vezes, as práticas pedagógicas desenvolvidas no campo escolar. Ademais, o ensaio aponta como as práticas pedagógicas/clínicas desenvolvidas recriam a forma de ser criança surda circunscrita à infância. Nesse sentido, podemos pensar um espaço pedagógico, conforme destacam Masschelein e Simons (2014), que se ocupe com a diferença surda no espaço da educação infantil. No entanto, como podemos pensar a constituição de um espaço pedagógico quando lidamos com crianças que cambiam entre esses dois territórios: infância e surdez? O que a pedagogia da diferença surda poderia propor a esses sujeitos? Como poderíamos construí-la? Poderíamos construí-la nessas fronteiras?

De acordo com Silva (2005), o processo de fixação de uma identidade é uma impossibilidade apesar de ser uma tendência. $\mathrm{O}$ autor ainda afirma que cruzar fronteiras pode significar passar livremente de um território simbólico para outro. Moverse e não respeitar os sinais que demarcam os territórios das diferentes identidades.

A possibilidade de "cruzar fronteiras" e de "estar na fronteira", de ter uma identidade ambígua, indefinida, é uma demonstraçáo do caráter "artificialmente" imposto das identidades fixas. O "cruzamento de fronteiras" e o cultivo propositado de identidades ambíguas é, entretanto, ao mesmo tempo uma poderosa estratégia política de questionamento das operaçóes de fixação da identidade. (SILVA, 2005, p. 89).

Em nosso tempo, a proposta educacional prevista para o sujeito surdo nas políticas e nas práticas se dá pelo que chamamos de práticas bilíngues. Trata-se de pensar uma pedagogia visual que se constitui nas línguas e nas relaçóes com as narrativas e os movimentos surdos, levando em conta a historicidade do grupo, tendo como base uma proposta educacional bilíngue em que a língua de instrução é a língua de sinais e a língua portuguesa é adquirida como segunda língua. É nessa direção que devem ser levadas a construção de práticas com crianças surdas e a compreensão de que essas crianças são sujeitos de suas próprias histórias, que podem se narrar e que precisam da Língua de Sinais para transitar nas fronteiras da infância e da surdez.

Para concluir, apresentamos resultados à pesquisa de Vieira-Machado (2010), resultados que destacam fatores apontados pelos narradores surdos e que são/podem ser considerados como alguns dos princípios disparadores de práticas educativas voltadas para as pessoas surdas: a) a valorização da língua de sinais como a primeira língua do surdo; b) um currículo acessível em língua de sinais; c) a relação surdo-surdo: a constituição das marcas culturais ; d) a busca por uma pedagogia visual e bilíngue. 


\section{Referências}

BRASIL. Lei federal n. 10.436, de 24 de abril de 2002. Disponível em: <http://www.planalto.gov.br/ccivil_03/leis/2002/L10436.htm>. Acesso em: 10 jul. 2015.

Decreto-lei n. 5.626, de 22 de dezembro de 2005. Diário Oficial [da] República Federativa do Brasil, Brasília, 23 de dez. 2005. Seção 1, p. 30.

BIESTA, G. Para além da aprendizagem: educação democrática para um futuro humano. Belo Horizonte: Autêntica editora, 2013.

BUJES, M. I. E. Infância e maquinarias. Rio de Janeiro: DP\&A, 2002.

COSTA, L. M. Traduçóes e marcas culturais dos surdos capixabas: os discursos desconstruídos quando a resistência conta a história. 2007. Dissertação (Mestrado em Educação) - Programa de Pós-Graduação em Educação, Universidade Federal do Espírito Santo, Vitória, 2007.

COUTO-LENZI, Á. ; PERDONCINI, G. Audiçáo: é o futuro da criança surda. Rio de Janeiro: AIPEDA, 1996.

EDUCAÇÃO. Documento final do I Seminário "Surdos um olhar sobre as práticas em Educação". Realizado em Caxias do Sul em Setembro de 2001. Caxias do Sul, 2001.

. A educaçáo que nós surdos queremos. Documento elaborado pela comunidade surda a partir do PréCongresso ao V Congresso Latino Americano de Educação Bilíngue para Surdos, Porto Alegre, 1999.

FOUCAULT, M. Microfísica do poder. 21. ed. Rio de Janeiro: Graal, 2005.

GALLO, S.; SOUZA, R. M. de. Educaçáo do preconceito: ensaios sobre poder e resistência. Campinas, SP: Editora Alínea, 2004.

GÓES, M. C. R. de. As contribuiçôes da abordagem histórico-cultural para a pesquisa em educaçấo especial. In: BAPTISTA, C. R.; CAIADO, K. R. M.; JESUS, D. M. (Orgs.). Educaçáo especial: diálogo e pluralidade. Porto Alegre: Editora Mediaçáo, 2008. p. 37-46.

LANE, H.; BAHAN, B. Ética do implante coclear em crianças pequenas: uma revisão e resposta de uma perspectiva do Mundo Surdo (texto traduzido), 1998.

LOPES, M. C. Surdez \& educação. Belo Horizonte: Autêntica, 2007.

MASSCHELEIN, J.; SIMONS, M. A pedagogia, a democracia e a escola. Belo Horizonte: Autentica, 2014.

PINO, A. Infâncias e cultura: semelhanças e diferenças. In: GALLO, S.; SOUZA, R. M. de. Educaçáo do preconceito: ensaios sobre poder e resistência. Campinas, SP: Editora Alínea, 2004.

PLAISANCE, E. Denominaçóes da infância: do anormal ao deficiente. Educaçáo \& Sociedade, Campinas, v. 26, maio/ago., 2005. p. 405-417.

SARMENTO, M. J. Geraçōes e alteridade: Interrogaçōes a partir da sociologia da Infância. Educaçáo \& Sociedade, Campinas, v. 26, maio/ago., 2005. p. 361-378.

SCLIAR, M. Um país chamado infância. 3. ed. Coleção Para Gostar de Ler, v. 18. Crônicas. São Paulo: Editora Ática, 1997.

SILVA, T. T. da. A produção social da identidade e da diferença. In: SILVA, T. T. (Org.). Identidade e diferença: a perspectiva dos estudos culturais. Rio de Janeiro: Editora Vozes, 2005.

SKLIAR, C. Pedagogia (improvável) da diferença: e se o outro não estivesse aí? Rio de Janeiro: DP\&A, 2003.

VIEIRA-MACHADO, L. M. da C. Os surdos, os ouvintes e a escola: narrativas, traduçốes e histórias capixabas. Vitória: Edufes, 2010.

WRIGLEY, O. A política da surdez. Tradução não publicada do original: The politics of deafness. Washington: Gallaudet University Press, 1996.

\section{Notas}

${ }^{1}$ Filme de Pedro Almadóvar produzido em 2002 que conta uma história ambientada Madri, local que é morada de Benigno Martin (Javier Cámara), um enfermeiro que reside em um apartamento que fica em frente a academia de balé comandada por Katerina Bilova (Geraldine Chaplin). Ele fica na janela da sua casa observando os ensaios com especial atençâo a uma das estudantes de Katerina, Alicia Roncero (Leonor Watling). Quando Alicia é ferida em um acidente de 
carro, acaba internada no hospital onde ele trabalha. Benigno cuida dela, em coma, com um cuidado acima do normal. Durante todo o tempo em que Alicia fica em coma no hospital Benigno fala com ela. Disponível em: < http://www. adorocinema.com/filmes/filme-28629/>. Acesso em: 16 jul. 2015.

${ }^{2}$ As histórias de Clara e Joẫo foram extraídas das vivências de uma das autoras como professora de surdos e pesquisadora da educação de surdos no âmbito da educação especial.

\section{Correspondência}

Lucyenne Matos da Costa Vieira Machado - Universidade Federal do Espírito Santo, Centro Biomédico. Rua Maruípe. CEP: 29000-000 - Vitoria, Espírito Santo - Brasil.

E-mail: luczarina@yahoo.com.br - sonia.victor@hotmail.com

Recebido em 21 de junho de 2015

Aprovado em 08 de agosto de 2015 